\title{
Variation and Heritabilities of Antioxidant Activity and Total Phenolic Content Estimated from a Red Raspberry Factorial Experiment
}

\author{
Ann Marie Connor \\ HortResearch, Ruakura Research Centre, Private Bag 3123, Hamilton, New Zealand \\ M. Joseph Stephens, Harvey K. Hall, and Peter A. Alspach \\ HortResearch, Nelson Research Centre, P.O. Box 220, Motueka, New Zealand
}

AdDitional INDEX words. Rubus sp., raspberry breeding, berry weight, genetic correlation

\begin{abstract}
Variance components and narrow-sense heritabilities were estimated for antioxidant activity (AA), total phenolic content (TPH), and fruit weight in red raspberry (Rubus idaeus L.) fruit from offspring of a factorial mating design. Forty-two full-sib families utilizing seven female and six male parents were evaluated in each of two years in Motueka, New Zealand. In a single year, values within individual half-sib families ranged as widely as $25.3-79.4 \mu \mathrm{g} \cdot \mathrm{g}^{-1}$ fruit for AA, 205-597 mg/100 g fruit for TPH, and 1.06-7.69 $\mathrm{g}$ for fruit weight. Analyses of variance for these three variates demonstrated significant parental source variation in both individual and combined year analyses. For AA and TPH, female parental effects accounted for $\approx 7 \%$ to $19 \%$ of total variation, while male effects accounted for $\approx 6 \%$ to $8 \%$. A partially pigment deficient $R$. parvifolius $L$. derivative female parent accounted for some of these differences. Female $\times$ male parent interaction was not significant for AA and TPH and was marginally significant for fruit weight in combined year analysis. Year had a significant effect on the overall mean AA and TPH, but contributed less than genetic effects to the overall variation in all three traits. Interactions of year with genetic effects were not statistically significant for AA or TPH, indicating that between-year rank or scale changes among families were negligible. The largest proportion of variation was found within rather than among full-sib families. However, variation among plots within full-sib families accounted for $12 \%$ to $19 \%$ of total variation, indicating environmental differences accounted for some of the observed within-family variation in AA and TPH. Antioxidant activity and TPH were highly phenotypically correlated $(r=0.93)$; their genetic correlation $(r=0.59)$ implies that substantial additive genetic factors underlie the phenotypic correlation, but that nonadditive genetic or environmental influences are also important. Both AA and TPH were weakly negatively phenotypically correlated with fruit weight $(r=-0.34$ and -0.33 , respectively), but the corresponding genetic correlations were close to zero. Thus, selection for both high AA or TPH and high fruit weight is possible. Narrow-sense heritability estimates based on variance components from combined year data were $h^{2}=0.54,0.48$, and 0.77 for AA, TPH, and fruit weight, respectively. These estimates imply a rapid response to selection is possible.
\end{abstract}

Fruit and vegetables supply to the human diet "non-nutrient" compounds as well as providing macro- and micro-nutrients. Included among the non-nutrient substances are polyphenolic compounds, including the flavonoids (e.g., anthocyanins, flavanols, flavonols, flavanones), as well as simple phenolic compounds such as phenolic acids. These polyphenolics and simple phenolics are present only in plant food sources of our diets and are thought to have a role in maintaining human health. Most epidemiological studies support the hypothesis that higher intakes of flavonoids are associated with lowered risk of acquiring or dying from certain chronic diseases in a number of populations (Commenges et al., 2000; Geleijnse et al., 2002; Hertog et al., 1997; Hirvonen et al., 2001; Knekt et al., 2002). In vitro and in vivo studies provide further evidence of the bioactivity of these compounds (for review, see Middleton et al., 2000). The mechanisms by which phenolic compounds confer their benefits are not entirely known, but appear to be due, in part, to their antioxidant activity (AA). Increased consumption of antioxidants has been shown to alleviate some of the adverse effects that are associated with cellular and tissue oxidation. For example, dietary inclusion of high-antioxidant

Received for publication 3 Oct. 2004. Accepted for publication 27 Nov. 2004. We thank Patricia Harris-Virgin and Laura Barnett for technical assistance. Funding for this work was from the New Zealand Foundation of Research Science and Technology project number CO6X0214 (Emerging Horticultural Export Crops programme). fruit or vegetable slowed (and in some cases reversed) the agerelated decline in neural and motor function in rats (Joseph et al., 1999), while supplementation with antioxidant vitamin and mineral supplements reduced the risk of developing one type of age-related eye disease in humans (senile macular degeneration) (Age-Related Eye Disease Study Research Group, 2001).

One way to increase the intake of antioxidants is greater consumption of fruit and vegetables. Many fruit, particularly berries and cane fruit, are rich sources of phenolic antioxidants (Kähkönen et al., 2001; Proteggente, et al., 2002; Wang, et al., 1996). Another option is to increase the levels of antioxidants in plant foods through breeding. This approach can succeed if the variability and heritability of the AA trait is indicative that progress through breeding is feasible. Connor et al. (2002a) demonstrated a moderate heritability for AA, total phenolic content (TPH) and anthocyanin content in blueberry (Vaccinium L. species) from a North American breeding program, using offspring-midparent regression. Connor et al. (2002b) confirmed a high level of variability in these traits among genotypes from the same breeding program, and high phenotypic correlations among the traits, while Howard et al. (2003) confirmed significant variability among blueberry selections and cultivars in another North American breeding program. Thus, breeding for higher AA appears realistic for blueberry.

Rubus L. species are also reported to demonstrate high levels of AA, with variation among species (Deighton et al., 2000; 
Moyer et al., 2002). Thus, they too may be candidates for breeding for higher antioxidant content. The current study reports the heritability of AA and phenolic content in red raspberry (Rubus idaeus), based on a factorial breeding design using parental genotypes from a New Zealand breeding program, followed for two harvest seasons.

\section{Materials and Methods}

Plants. Seven female and six male red raspberry cultivars and selections in the HortResearch Rubus breeding program were used for glasshouse hybridizations in a factorial mating design in 1998. The genotypes were selected without regard to their AA, TPH, or anthocyanin content. However, it was visually apparent that fruit from one female parent, an offspring of an open-pollinated $R$. parvifolius $\times R$. idaeus hybrid (referred to as " $R$. parvifolius derivative"), was partially pigment deficient. Seeds were germinated in July 1999 and seedlings were grown in pots of bark-based soil mix until July 2000, at which time they were planted in nonfumigated soil at the HortResearch-Nelson Research Centre research orchard in Motueka, New Zealand (lat. $41^{\circ} 6^{\prime} \mathrm{S}$, long. $172^{\circ} 58^{\prime} \mathrm{E}$ ). Plants were set in a resolvable randomized incomplete Latinized block design (John and Williams, 1995) with four (full-sib) plants per plot, 13 plots per row, four rows per replication, and four replications (i.e., 16 plants per full-sib family). Thirty of the 42 full-sib families were spiny, two were spineless, and 10 showed segregation for spines. Spiny and spineless offspring of the segregating families were separately represented in the design, for a total of 52 plots per replication. Plants were trained to a three-wire vertical trellis system and contained within bird-proof netting. Spacing was $1 \mathrm{~m}$ between plants and $3 \mathrm{~m}$ between rows. Plants were maintained using standard orchard practice for fertilization, weed control, disease control, and irrigation. Primocanes were thinned only as necessary to separate plants, but otherwise were not suppressed and were not physically separated from floricanes. Spent floricanes were removed during dormancy, at which time new floricanes were tied (bunched) to the top trellis wire and tipped to $10 \mathrm{~cm}$ above the wire. Two years after field planting, plants were evaluated and the center two plants from each plot were tagged for use in this study, unless they appeared unhealthy or unable to provide sufficient fruit for harvest, in which case the adjacent plant was chosen. The same plants were used for the 2002-03 (2002 season; year 1) and 2003-04 (2003 season; year 2) harvest seasons. Plant death prior to first evaluation precluded assessment of two plots (one spiny and one spineless) in one replication of one full-sib family ('Kohatu' $\times$ 'Kaituna'), and of one plot of the spineless offspring of another full-sib family ('Kohatu' $\times$ 88304ROC6). Replacement with one spiny plant in the latter instance permitted additional assessment of a "single-plant plot" of spiny offspring from this family. Thus, a total of 411 plants were tagged. There was no further mortality between the first and second years of the study, although the health of some plants deteriorated. Most of the factorial parental genotypes were growing in the same orchard in nearby rows and fruit was also harvested from these plants.

FruIT. Approximately $100 \mathrm{~g}$ of sound, ripe but not over-ripe, fruit were harvested from each plant in each season. In preliminary assessments in our lab, AA and phenolic content appeared to change with date of harvest for some genotypes (data not shown). To detect and adjust for bias due to differences in time of harvest, in 2002, fruit were harvested in early-season in replication 1, midseason in replications 2 and 3, and late-season in replication 4. In 2003, fruit were harvested in early-season in replication 4, mid-season in replications 2 and 3, and late-season in replication 1. Earlyseason was judged as $>10 \%$ but $<35 \%$ total fruit ripe, midseason as $35 \%$ to $65 \%$ total fruit ripe, and late-season as $>65 \%$ total fruit ripe. Plants were judged individually for fruit ripeness; hence, not all plants in a replication were harvested simultaneously. Plants with small amounts of fruit required consecutive harvests, from which fruit were combined into a single sample, but collection of $95 \%$ of genotypes were completed in one or two harvests in 2002, and $93 \%$ in 2003. Fruit from parental genotypes were harvested in midseason. Fruit were collected by two trained individuals during the morning $(\approx 0600-0900 \mathrm{~h}$ ), placed into plastic punnets and held in the shade at ambient temperature $\left(\approx 11-13^{\circ} \mathrm{C}\right)$ for up to $3 \mathrm{~h}$. They were weighed, counted (to allow the computation of average fruit weight), and frozen at $-20^{\circ} \mathrm{C}\left(-40^{\circ} \mathrm{C}\right.$ in 2003$)$ until firm and then transferred to plastic storage bags and maintained at the same temperature. Following completion of harvest, which lasted approximately 4-5 weeks, samples were shipped on dry ice without thawing to laboratory facilities in Palmerston North, where they were stored at $-85^{\circ} \mathrm{C}$ until extraction.

ExTRACTION. All preparation proceeded under reduced-light conditions or under safety light in a fume exhaust hood. An entire 100 -g sample of fruit was disaggregated into individual drupelets while still frozen, by applying firm manual pressure to the bag of fruit. Drupelets were mixed well, and a 20 -g sample was weighed into a screw-capped 250 -mL glass bottle to which $100 \mathrm{~mL}$ solvent [ethanol (96\%) water:glacial acetic acid, 80:20:1] was added. The mixture was homogenized (Ultra-Turrax T 25 basic; LKA Works, Sengalore, Malaysia) at highest speed for $1 \mathrm{~min}$. The homogenizer probe was rinsed twice with water and once with solvent between samples. Sample bottles were stored for $48 \mathrm{~h}$ in the dark at $4{ }^{\circ} \mathrm{C}$. After storage, the homogenate was mixed briefly and allowed to equilibrate toward room temperature $\left(\approx 18^{\circ} \mathrm{C}\right)$ for $1 \mathrm{~h}$, after which two $10-\mathrm{mL}$ subsamples were removed and centrifuged at $1500 g_{\mathrm{n}}$ (Labofuge GL; Heraeus Christ, Osterode, Germany) for $20 \mathrm{~min}$ at room temperature. Four milliliters of supernatant from each subsample were stored in separate amber screw-cap vials at $-20^{\circ} \mathrm{C}$ until analysis. For each assay, single determinations were made on each subsample, since previous studies demonstrated that variation between duplicate determinations on single subsamples was negligible (data not shown).

TOTAL PHENOLIC CONTENT. A Folin-Ciocalteu reagent-based method (Coseteng and Lee, 1987) was used, modified to allow 90 min for color development. Extracts diluted 1:15 with water were interpreted against a standard curve of gallic acid, which was linear from $0-70 \mu \mathrm{g} \cdot \mathrm{mL}^{-1}$. Results are reported as gallic acid equivalents [GAE (mg/100 $\mathrm{g}$ fruit)].

Antioxidant ACTIVITy. The ferric-reducing antioxidant power [FRAP, also known as ferric-reducing activity of plasma (Benzie and Strain, 1996)] assay was used, as modified by Deighton et al. (2000). Absorbance of the colored product [ferrous tripyridyltriazine (TPTZ) complex] at $593 \mathrm{~nm}$ was recorded 4 min after the addition of extract or standard to the FRAP reagent (DU640 spectrophotometer; Beckman, Fullerton, Calif.). Standard curves using Trolox $(0-250 \mu \mathrm{M})$ and ferrous sulfate $(0-500 \mu \mathrm{M})$ were run with each set of extracts, and were linear within these ranges. In general, activity of Trolox was approximately twice that of ferrous sulfate, which concurs with Benzie and Strain (1996). Dilution of extracts 1:25 in water was sufficient to give absorbance of the reaction product well within the limits of the standard curves. Statistical analyses were performed using assay data expressed both in ferrous sulfate standard equivalents and in 
Trolox standard equivalents. Significance testing was identical for both sets of equivalents with the exception of one value, noted in the Results section. Assay results are reported as ferrous sulfate (FE) equivalents in $\mu \mathrm{mol} \cdot \mathrm{g}^{-1}$ fruit.

Statistical analyses. Parents, years, replications, rows and plots were treated as random factors. Analyses of variance (ANOVAs) and variance components were calculated with plot nested within female $\times$ male. Restricted maximum likelihood (REML) was used to estimate variance components. Narrowsense heritability estimates on an individual plant basis using variance components were based on pooled female and male sources (Hallauer and Miranda, 1981), as degrees of freedom were similar for females and males (six and five, respectively). For single year data:

$$
h^{2}=\frac{4 \frac{\left(f \sigma_{f p}^{2}+m \sigma_{m p}^{2}\right)}{f+m}}{\sigma_{f p}^{2}+\sigma_{m p}^{2}+\sigma_{f p \times m p}^{2}+\sigma_{e}^{2}}
$$

For combined year data:

$$
h^{2}=\frac{4 \frac{\left(f \sigma_{f p}^{2}+m \sigma_{m p}^{2}\right)}{f+m}}{\sigma_{f p}^{2}+\sigma_{m p}^{2}+\sigma_{f p \times m p}^{2}+\sigma_{f p \times \text { year }}^{2}+\sigma_{m p \times \text { year }}^{2}+\sigma_{f p \times m p \times \text { year }}^{2}+\sigma_{p l o t \text { rep } \times \text { year }}^{2}+\sigma_{e}^{2}}
$$

where $f=$ number of female parents, $m=$ number of male parents, $\sigma_{f p}^{2}=$ variance among female parent half-sib families, and $\sigma_{m p}^{2}=$ variance among male parent half-sib families, $\sigma_{f p \times m p}^{2}=$ variance of the female parent $\times$ male parent interaction, $\sigma_{f p \times y e a r}^{2}=$ variance of the female parent $\times$ year interaction, $\sigma^{2}{ }_{m p \times \text { year }}=$ variance of the male parent $\times$ year interaction, $\sigma_{\text {plot } r e p \times y e a r}^{2}=$ variance of the plot within replication $\times$ year interaction, and $\sigma_{e}^{2}=$ the residual environmental variance. Narrow-sense heritability estimates based on offspring-midparent regression were calculated as the slope of the line of least-squares regression, and midparent values were calculated as the mean of the female parent and male parent values for each full-sib family. In order to minimize upward bias due to environmental covariance, since parents and offspring were grown in the same location both years, the values of the offspring from 1 year were regressed against the midparent values from the other year. Genotypic correlations were computed as:

$$
\frac{\operatorname{Cov}_{A}(X, Y)}{\sqrt{V_{A}(X) \times V_{A}(Y)}}=\frac{(f+m) \times \operatorname{Cov}_{A}(X, Y)}{4 \sqrt{\left[f \sigma_{f p}^{2}(X)+m \sigma_{m p}^{2}(X)\right]\left[f \sigma_{f p}^{2}(Y)+m \sigma_{m p}^{2}(Y)\right]}}
$$

where $\operatorname{Cov}_{A}(X, Y)$ is the additive genetic covariance between traits $X$ and $Y, \sigma_{f p}^{2}(X)$ and $\sigma_{f p}^{2}(Y)$ are the variances among female parent half-sib families for traits $X$ and $Y$, respectively, and $\sigma_{m p}^{2}(X)$ and $\sigma^{2}{ }_{m p}(Y)$ are the variances among male parent half-sib families for traits $X$ and $Y$, respectively. The covariance between simple family means was used as an estimate of the additive genetic covariance (Dieters 1996). Pearson's correlations for phenotype were calculated on a genotype mean basis. For AA and TPH, the mean value of the two extract subsamples was used in all analyses, as the variation between subsamples was not of interest and was generally tiny. Satterthwaite's (1946) approximation for denominator degrees of freedom, as described by Steel et al. (1997), was used where required. Analyses were performed in S-Plus, version 6.1 (Insightful Corp, Seattle, Wash.)

\section{Results}

In 2002 and 2003, fruit were collected and analyzed from all 411 chosen factorial genotypes. One genotype yielded fewer than $20 \mathrm{~g}$ of sound fruit in 2003; laboratory extraction was adjusted accordingly. None of the factorial genotypes required more than four harvests to provide $100 \mathrm{~g}$ fruit in 2002, while 11 genotypes required more than four harvests in 2003 (data not shown). Virtually all plants requiring more than four harvests were remarkable for small size, poor growth or low vigor, sparse fruit production, and slow fruit ripening. Some demonstrated partial necrosis of canes or laterals. Fruit was harvested from all female parents in both years, from four of six male parents in 2002, and from five male parents in 2003.

ANOVAs for AA, TPH, and fruit weight in the families segregating for spines demonstrated no significant variation between spiny and spineless groups in either single or combined years. Thus, no distinction between spiny and spineless offspring was made in the remaining analyses. Means in each field replication were determined in both years for the three traits. Although differences among replications were noted, no pattern emerged to suggest that the time of harvest (early-, mid-, or late-season for each genotype within a replication; see Materials and Methods) uniformly or reliably influenced the values for these traits. The ranges in AA, TPH, and fruit weight among the half-sib families showed considerable overlap in each year (Table 1). The within half-sib family range for AA varied from $19.7-37.2 \mu \mathrm{mol} \cdot \mathrm{g}^{-1}$ fruit in 2002 , and $19.5-54.1 \mu \mathrm{mol} \cdot \mathrm{g}^{-1}$ fruit in 2003 ; for TPH, this range varied from $192-299 \mathrm{mg} / 100 \mathrm{~g}$ fruit in 2002 , and $178-392 \mathrm{mg} / 100$ $\mathrm{g}$ fruit in 2003; and for fruit weight it varied from $2.24-5.07 \mathrm{~g}$ in 2002, and 2.75-6.63 g in 2003. The $R$. parvifolius derivative progeny had the lowest mean AA and TPH and the smallest lowrange values for these variables in both years.

The ANOVAs for AA and TPH demonstrated significant parental source variation in both the individual year and combined year analyses (Table 2). However, there was no significant female $\times$ male parent interaction (specific combining ability in a fixed effects model) for either of these traits. The combined-year analyses indicated that year had a significant effect on the overall mean AA and TPH for the factorial population. Interactions of year with either of the parental sources or their interaction were not significant, however, indicating that substantial rank or scale changes in AA or TPH between years were not present among half-sib or full-sib families. Note that although year effect on TPH is clearly demonstrated $(P=0.007)$, year effect on AA is marginal $(P=0.063$ for AA expressed in ferrous sulfate standard equivalents, and $P=0.043$ when expressed in Trolox standard equivalents). In both 2003 and the combined year analyses, significant variation for AA and TPH was observed among plots within full-sib families.

Parental source variation is also evident for fruit weight (Table 2). Although no female $\times$ male interaction for fruit weight was noted in the ANOVAs for 2003, there was an indication that this interaction was present in the 2002 analysis $(P=0.039$; combined year analysis: $P=0.063)$. In contrast to the analyses for AA and TPH, a significant year effect for fruit weight was not observed. Interactions of year with parental components were also non-significant. Variation among plots within full-sib families was significant in combined year analysis but not in single year analyses.

Female parental effects tended to account for a greater proportion of variation $(\approx 7 \%$ to $19 \%)$ than male parents ( $\approx 6 \%$ to $8 \%)$ 
Table 1. Mean values of antioxidant activity (AA), total phenolic content $(\mathrm{TPH})$, and fruit weight for red raspberry factorial parents $(\mathrm{F}=$ female, $M=$ male) and mean values (ranges) for their half-sib families in 2002 and 2003 ( $\mathrm{n}=48-87$ genotypes per half-sib family).

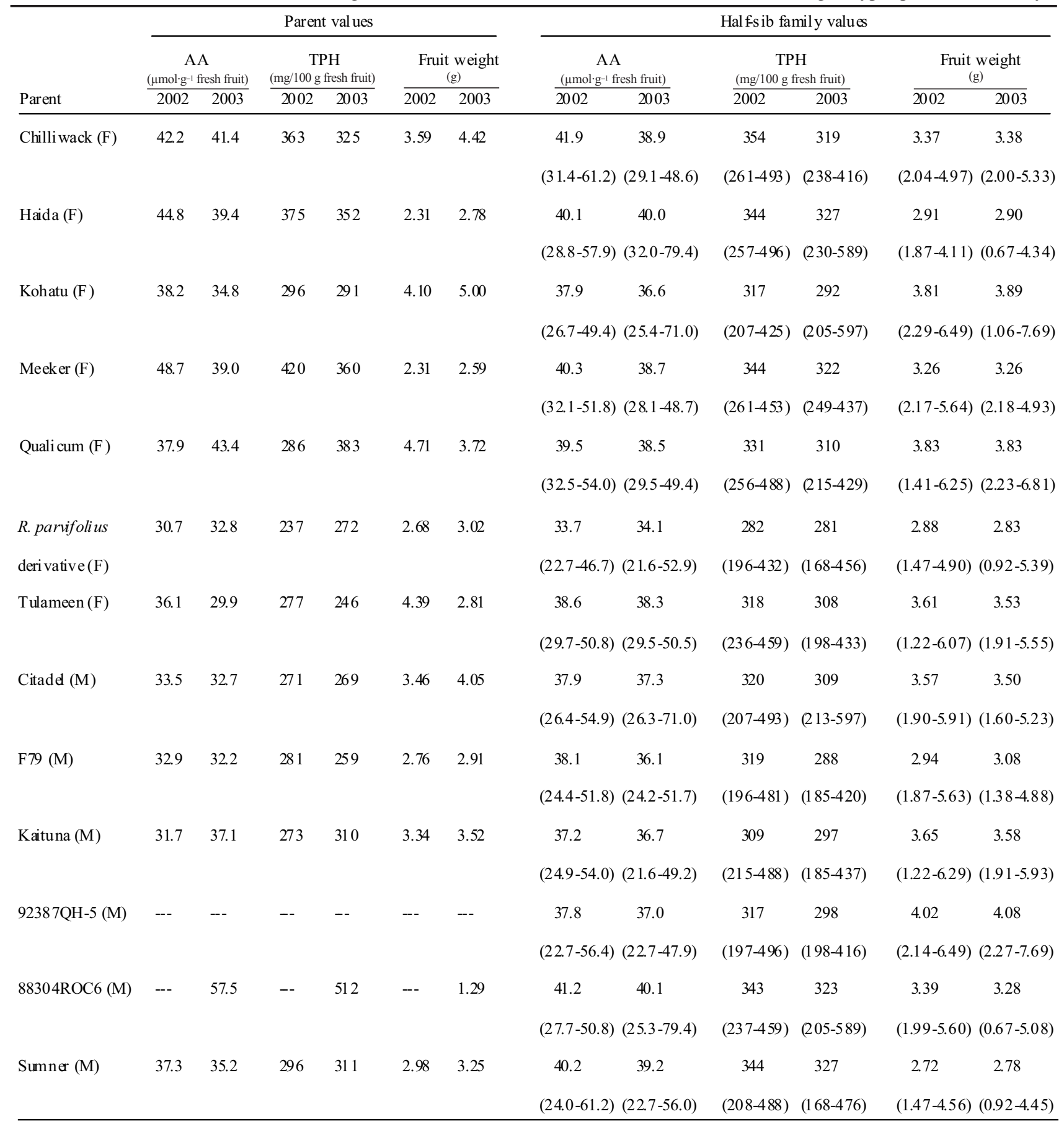

for AA and TPH (Table 3). The differences between female and male parental contributions to variation are much larger in 2002 than in 2003. As noted above, the $R$. parvifolius derivative parent differed from other female parents in that its fruit were partially pigment deficient; fruit from many of its offspring were also pigment deficient. Because the pigment deficiency could reflect defects in phenolic compound production, inclusion of the $R$. parvifolius derivative might account for the differences between female and male parental contributions to variance. Exclusion of $R$. parvifolius derivative progeny reduced the contribution of female parent effects to the total variation in AA and TPH. For example, in the combined year analyses the contribution to varia- tion in AA dropped from $12 \%$ to 3\%, and in TPH it dropped from $11 \%$ to $4.5 \%$ (data not shown). However, exclusion of offspring from other female parents had minimal effect on the variance component distribution of these variables (data not shown).

Variance component analyses were performed excluding data from the 11 genotypes that required more than four collections to obtain $100 \mathrm{~g}$ fruit in 2003. As described above, these plants showed poor vigor and signs indicative of stress. Exclusion of these data increased the female contribution to the total variance in AA and TPH by $\approx 2 \%$ (i.e., from $\approx 10 \%$ to $\approx 12 \%$ ) (data not shown).

Female and male effects contributed nearly equally to the variation observed in fruit weight, $\approx 14 \%$ to $15 \%$ for females and 
Table 2. Analyses of variance for antioxidant activity (AA; FRAP method with ferrous sulfate standard), total phenolic content (TPH), and fruit weight or fruit harvest in 2 years from red raspberry factorial mating design based on seven female and six male parents ( $n=411$ genotypes).

\begin{tabular}{|c|c|c|c|c|c|c|c|c|c|c|}
\hline \multirow[b]{3}{*}{ Source } & \multirow[b]{3}{*}{$\mathrm{df}$} & \multicolumn{3}{|c|}{ AA } & \multicolumn{3}{|c|}{ TPH } & \multicolumn{3}{|c|}{ Fruit weight } \\
\hline & & \multicolumn{3}{|l|}{ Mean } & \multicolumn{3}{|l|}{ Mean } & \multicolumn{3}{|l|}{ Mean } \\
\hline & & squares & F-ratio & $P$ & squares & F-ratio & $\mathrm{P}$ & squares & F-ratio & $\mathrm{P}$ \\
\hline \multicolumn{11}{|l|}{$\underline{2002}$} \\
\hline Rep & 3 & 168 & 7.28 & $<0.001$ & 12421 & 5.68 & $<0.001$ & 0.27 & 0.47 & 0.701 \\
\hline Female (F) & 6 & 374 & 14.39 & $<0.001$ & 31823 & 13.87 & $<0.001$ & 9.77 & 11.03 & $<0.001$ \\
\hline Male (M) & 5 & 243 & 9.34 & $<0.001$ & 18269 & 7.96 & $<0.001$ & 12.41 & 14.01 & $<0.001$ \\
\hline $\mathrm{F} \times \mathrm{M}$ & 30 & 26 & 0.89 & 0.627 & 2295 & 1.01 & 0.464 & 0.89 & 1.59 & 0.039 \\
\hline Plot within F x M & 135 & 29 & 1.25 & 0.069 & 2275 & 1.04 & 0.395 & 0.56 & 0.99 & 0.525 \\
\hline Residuals & 231 & 23 & & & 2188 & & & 0.56 & & \\
\hline \multicolumn{11}{|l|}{$\underline{2003}$} \\
\hline Rep & 3 & 158 & 5.77 & $<0.001$ & 12415 & 5.18 & 0.002 & 1.77 & 3.08 & 0.028 \\
\hline Female $(F)$ & 6 & 207 & 5.63 & $<0.001$ & 15561 & 4.87 & 0.001 & 10.35 & 12.68 & $<0.001$ \\
\hline Male (M) & 5 & 210 & 5.71 & $<0.001$ & 17106 & 5.36 & 0.001 & 11.29 & 13.83 & $<0.001$ \\
\hline $\mathrm{F} \times \mathrm{M}$ & 30 & 37 & 0.90 & 0.616 & 3192 & 1.04 & 0.425 & 0.82 & 1.21 & 0.234 \\
\hline Plot within F x M & 135 & 41 & 1.49 & 0.004 & 3076 & 1.28 & 0.049 & 0.68 & 1.18 & 0.137 \\
\hline Residuals & 231 & 27 & & & 2397 & & & 0.57 & & \\
\hline \multicolumn{11}{|l|}{ Combined years } \\
\hline Rep & 3 & 185 & 7.28 & $<0.001$ & 10145 & 4.39 & 0.005 & 0.92 & 1.63 & 0.182 \\
\hline Female (F) & 6 & 549 & 9.15 & $<0.001$ & 43832 & 7.39 & 0.001 & 20.00 & 14.82 & $<0.001$ \\
\hline Male (M) & 5 & 444 & 11.73 & $<0.001$ & 33956 & 8.38 & $<0.001$ & 23.42 & 15.43 & $<0.001$ \\
\hline Year $(\mathrm{Y})$ & 1 & 201 & $8.38(11.43)^{\mathrm{z}}$ & $0.063(0.043)^{z}$ & 66500 & 19.31 & 0.007 & 0.00 & 0.01 & 0.951 \\
\hline $\mathrm{F} \times \mathrm{M}$ & 30 & 46 & 0.76 & 0.806 & 4010 & 0.94 & 0.556 & 1.48 & 1.53 & 0.063 \\
\hline F x Y & 6 & 32 & 1.84 & 0.126 & 3400 & 2.30 & 0.061 & 0.10 & 0.44 & 0.847 \\
\hline $\mathrm{Mx} \mathrm{Y}$ & 5 & 10 & 0.56 & 0.733 & 1522 & 1.03 & 0.418 & 0.27 & 1.18 & 0.340 \\
\hline Plot within F x M & 135 & 57 & 3.95 & $<0.001$ & 4166 & 2.98 & $<0.001$ & 0.99 & 3.91 & $<0.001$ \\
\hline $\mathrm{F} \times \mathrm{M} \times \mathrm{Y}$ & 30 & 17 & 1.19 & 0.249 & 1478 & 1.06 & 0.399 & 0.23 & 0.89 & 0.629 \\
\hline Plot within F $\times$ M x Y & 135 & 15 & 0.57 & 1.000 & 1398 & 0.60 & 1.000 & 0.25 & 0.45 & 1.000 \\
\hline Residuals & 465 & 25 & & & 2313 & & & 0.57 & & \\
\hline
\end{tabular}

${ }^{2}$ Numbers in parentheses represent the analysis of variance F ratio and corresponding $P$ value for antioxidant activity by FRAP method, when expressed in Trolox standard equivalents.

$16 \%$ to $20 \%$ for males. Reduction in the female effect contribution to total variation in fruit weight was minor with the exclusion of $R$. parvifolius derivative progeny from the analysis. Exclusion of the 11 genotypes requiring more than four collections in 2003 had negligible impact on the variance component contributions for fruit weight.

Year effect contributed less than genetic effects to the overall variation in AA, TPH, and fruit weight (Table 3). The residual component, constituting the within-plot genetic and within-plot environmental effects and experimental error, accounted for the largest proportion of variation for all three of the traits, approximately $54 \%$ to $63 \%$ in combined year analyses and up to $74 \%$ in single year analyses. Among-plot variation within families was also substantial (12\% to $19 \%$ ) in combined year analyses, although the variation was much less pronounced in 2002 than 2003.

Antioxidant activity and TPH were highly and positively phenotypically correlated $(r=0.93$, Table 4$)$ and showed substantial genetic correlation $(r=0.59)$. Antioxidant activity and TPH demonstrated weak, but significant, negative phenotypic correlations with fruit weight $(r=-0.34$ and -0.33 , respectively; 
Table 3. Variance component distributions (\%) for antioxidant activity (AA), total phenolic content (TPH), and fruit weight for individual and combined years in red raspberry factorial derived from seven female and six male parents $(\mathrm{n}=411$ genotypes).

\begin{tabular}{|c|c|c|c|c|c|c|c|c|c|}
\hline \multirow[b]{3}{*}{ Source } & \multicolumn{3}{|c|}{ AA } & \multicolumn{3}{|c|}{ ТPH } & \multicolumn{3}{|c|}{ Fruit weight } \\
\hline & & & Combined & & & Combined & & & Combined \\
\hline & 2002 & 2003 & years & 2002 & 2003 & years & 2002 & 2003 & years \\
\hline Rep & 3.4 & 3.2 & 1.6 & 2.9 & 3.4 & 1.1 & 0.0 & 1.1 & 0.1 \\
\hline Femal e (F) & 19.2 & 7.8 & 12.2 & 18.9 & 7.1 & 11.1 & 13.9 & 14.4 & 14.5 \\
\hline Male (M) & 7.7 & 5.6 & 6.7 & 7.0 & 6.2 & 6.5 & 19.9 & 16.2 & 17.4 \\
\hline Year (Y) & -- & -- & 1.1 & --- & -- & 4.7 & - & -- & 0.0 \\
\hline $\mathrm{F} \times \mathrm{M}$ & 0.0 & 0.0 & 0.0 & 0.0 & 0.0 & 0.0 & 3.6 & 2.2 & 2.5 \\
\hline $\mathrm{F} \times \mathrm{Y}$ & -- & -- & 0.3 & --- & --- & 0.7 & - & -- & 0.0 \\
\hline $\mathrm{MxY}$ & -- & -- & 0.0 & --- & --- & 0.0 & - & -- & 0.0 \\
\hline Plot within F x M & 5.6 & 13.5 & 18.5 & 1.0 & 9.4 & 13.1 & 0.8 & 3.1 & 11.9 \\
\hline $\mathrm{F} \times \mathrm{M} \times \mathrm{Y}$ & -- & -- & 0.0 & --- & -- & 0.0 & - & -- & 0.0 \\
\hline Plot within F $x$ M x Y & -- & --- & 0.0 & --- & --- & 0.0 & - & -- & 0.0 \\
\hline Residuals & 64.1 & 69.9 & 59.5 & 70.1 & 74.0 & 62.8 & 61.8 & 63.0 & 53.6 \\
\hline
\end{tabular}

Table 4. Genotypic (lower left) and phenotypic (uper right) correlations for antioxidant activity (AA), total phonlic content (TPH), and fruit weight of fruit harvest from red raspberry factorial in 2002 and 2003 ( $n=411$ genotypes each year).

\begin{tabular}{lccc}
\hline & AA & TPH & Fruit wt \\
\hline AA & --- & 0.93 & -0.33 \\
TPH & 0.59 & --- & -0.34 \\
Fruit weight & -0.07 & -0.013 & --- \\
\hline
\end{tabular}

$P<0.001)$. However, the equivalent genetic correlations were much closer to zero.

Narrow-sense heritability estimates on an individual plant basis were calculated based on variance components for AA, TPH, and fruit weight (Table 5). The heritabilities based on combined year data were moderate for both AA and TPH, $h^{2}=0.54$ and 0.48 , respectively. Heritability estimates for these two traits were lower in 2003 than 2002. In contrast, the heritability for fruit weight did not vary between years, $\left(h^{2}=0.72\right.$ and 0.66$)$, and for the combined years was moderate-high, $h^{2}=0.77$.

As noted above, exclusion of $R$. parvifolius derivative progeny from the variance component analyses substantially reduced female genetic contribution to the total variance for AA and TPH. Thus, variance component heritability estimates were also calculated following exclusion of $R$. parvifolius derivative progeny. For AA, heritabilities decreased from 0.61 (Table 5) to 0.32 (analysis not shown) in 2002, from 0.38 to 0.21 in 2003, and from 0.54 to 0.29 in combined years. For TPH, heritabilities decreased from 0.55 (Table 5) to 0.30 (analysis not shown) in 2002, from 0.33 to 0.22 in 2003 , and from 0.48 to 0.28 in combined years. Heritabilities for fruit weight changed from 0.72 (Table 5) to 0.62 (analysis not shown), from 0.66 to 0.61 , and from 0.77 to 0.73 for 2002, 2003, and combined years, respectively.

Heritability estimates were also calculated from variance components following exclusion of the 11 genotypes requiring more than four fruit collections in 2003. For AA and TPH, the estimates increased by $\approx 10 \%$ but for fruit weight there was little or no change in the estimate (data not shown).
Narrow-sense heritability estimates based on offspring-midparent regression were calculated and compared to the above estimates (Table 5). Two of the male parents were not assessed for $\mathrm{AA}, \mathrm{TPH}$, and fruit weight in both years, and thus the heritability estimates were based on data from the 11 parents (and their halfsib families) that were evaluated both years. The individual and combined year heritability estimates for TPH and AA obtained by offspring-midparent regression were similar to those obtained by variance components. Heritabilities of fruit weight based on 2002 and combined year data were higher, although well within standard error limits, when estimated from variance components than from offspring-midparent regression. The two methods yielded identical estimates for 2003 data.

Positive transgressive segregants for each trait were identified as those factorial genotypes whose 2-year mean exceeded that of its higher parent by at least 2 SDs; the SD was based on the values of the entire offspring population. For AA, one transgressive segregant was identified in each of four full-sib families while two were identified in one full-sib family. For TPH, one transgressive segregant was identified in each of seven full-sib-families. For both AA and TPH, 'Sumner' was the male parent for four of the transgressive segregants. Five of the six genotypes identified as transgressive segregants for AA were transgressive segregants for TPH. For fruit weight, four full-sib families each contained one transgressive segregant.

\section{Discussion}

Breeding for higher levels of a trait requires that there be substantial variation in the plant breeding population and a heritability that is sufficiently high to make ample improvement in the trait, warranting the expenditure for testing selections from successive generations. Previous studies have suggested that variation in AA and TPH exists among red raspberry cultivars. González et al. (2003) reported a total phenolic range of 113 to $179 \mathrm{mg} / 100 \mathrm{~g}$ fresh weight among four red raspberry cultivars grown in one season, and an antioxidant capacity [determined as 
Table 5. Narrow-sense heritability estimates (standard error) for antioxidant activity (AA), total phenolic content (TPH), and fruit weight in red raspberry fruit, based on variance component analysis of factorial design $(n=411$ in each 2002 and 2003) and on offspring-midparent regression analysis using factorial and parental data.

\begin{tabular}{cr}
$h^{2}$ by variance component & $h^{2}$ by offs pring-midparent \\
analysis & regression analysis \\
\hline
\end{tabular}

AA

$\begin{array}{lll}2002 & 0.61(0.15) & 0.56(0.22) \\ 2003 & 0.38(0.12) & 0.44(0.13) \\ \text { Combined years } & 0.54(0.27) & 0.44(0.12)\end{array}$

$\mathrm{TPH}$

$\begin{array}{lll}2002 & 0.55(0.10) & 0.55(0.20) \\ 2003 & 0.33(0.18) & 0.34(0.13) \\ \text { Combined years } & 0.48(0.15) & 0.44(0.12)\end{array}$

Fruit weight

$\begin{array}{lll}2002 & 0.72(0.33) & 0.61(0.20) \\ 2003 & 0.66(0.31) & 0.66(0.16) \\ \text { Combined years } & 0.77(0.31) & 0.61(0.12)\end{array}$

antiradical efficiency (i.e., the rate of DPPH radical quenching in grams per minute)] that ranged from $4.02 \times 10^{-4}$ to $10.15 \times 10^{-4}$ per $\mathrm{g}$ fruit. Correlation between total phenolics and free-radical scavenging activity was 0.83 . Liu et al. (2002) reported a TPH range of 359 to $512 \mathrm{mg} / 100 \mathrm{~g}$ fresh weight among four cultivars in one season, and antioxidant activity (determined by the total oxyradical scavenging capacity and expressed as median effective dose) that ranged from $802 \mu \mathrm{g} \cdot \mathrm{mL}^{-1}$ (least effective) to 312 $\mu \mathrm{g} \cdot \mathrm{mL}^{-1}$ (most effective). The correlation between TPH and AA was $r=0.99$. TPH and AA in individual genotypes have been reported by others (Kähkönen et al., 1999; Proteggente et al., 2002; Wada and $\mathrm{Ou}, 2002)$, but none of the reports have examined a mating design or the effect of year on these traits.

This study demonstrated that in our red raspberry factorial population, substantial variation exists in AA, TPH, and fruit weight. Narrow-sense heritability estimates for AA and TPH were moderate, and for fruit weight were moderate-high. Previous heritability estimates for AA and TPH were not identified in a search of the literature. However, Nestby (1994) reported a broad-sense heritability estimate of $H^{2}=0.42$ for fruit weight, based on 1 year of data from 10 offspring in each of two replications of 19 red raspberry families. Fejer and Spangelo (1974) reported a broadsense heritability estimate of $H^{2}=0.58$ for fruit weight among 14 replicated progenies of selections from selfed $\left(\mathrm{S}_{3}\right)$ red raspberry cultivars. Fejer (1977) reported data from red raspberry diallel crosses supporting predominantly additive inheritance for fruit weight, but with a significant nonadditive component as well. Our moderate-high narrow-sense heritability estimate for fruit weight in a factorial design generally concurs with the findings in the previous studies. However, we found that the female $\times$ male interaction was of only borderline significance, which contrasts with the significant specific combining ability Fejer (1977) reported. Fruit size in raspberry tends to decrease as the harvest season progresses, but this is unlikely to have had a major impact on our results since within each replicate the plants were harvested at a similar stage during the season where possible. Furthermore, exclusion of the 11 genotypes, which required more than four harvests in 2003, hardly changed the heritability estimate for fruit weight, in contrast to AA and TPH.

Our results suggest that reasonably rapid progress through breeding can be expected for these traits. The genetic advance in one cycle of selection can be predicted as $i \sigma_{p h} h^{2}$, where $i=$ selection intensity constant, $\sigma_{p h}=$ square root of the phenotypic variance in the unselected population, and $h^{2}=$ narrow-sense heritability (Poehlman and Sleper, 1995). Using the data from the factorial population and assuming a selection intensity of 5\% $(i$ $=2.063$ ), the predicted gain in AA is $7.3 \mu \mathrm{mol} \cdot \mathrm{g}^{-1}$ fruit based on 2002 data, $4.3 \mu \mathrm{mol} \cdot \mathrm{g}^{-1}$ fruit based on 2003 data, and $6.0 \mu \mathrm{mol} \cdot \mathrm{g}^{-1}$ fruit based on combined year data. Based on the population means for the individual and combined years, these gains represent increases of $19 \%, 11 \%$, and $16 \%$ over the unselected mean in 2002, 2003 , and combined years, respectively. For TPH, the predicted gains with a selection intensity of $5 \%$ are 63 $\mathrm{mg} / 100 \mathrm{~g}$ fruit (19\% increase), $35.5 \mathrm{mg} / 100 \mathrm{~g}$ fruit (12\% increase), and $50.1 \mathrm{mg} / 100 \mathrm{~g}$ fruit (16\% increase), based on 2002, 2003, and combined year data, respectively. For fruit weight, predicted gains are $1.36 \mathrm{~g}$ (40\% increase), $1.26 \mathrm{~g} \mathrm{(37 \%} \mathrm{increase),} \mathrm{and} 1.38 \mathrm{~g} \mathrm{(40 \%} \mathrm{increase)} \mathrm{based}$ on 2002, 2003, and combined year data. The predicted gain based on 2003 data for all three traits is considerably lower than that based on 2002 data, suggesting that combined year data may provide a more accurate prediction of genetic advance. Predicting gain per cycle also depends on accurate selection of individuals with high levels of the trait.

The above expected gains are based on all females, including the $R$. parvifolius derivative, and are encouraging in that they indicate that the lowering effect of this parent on AA and TPH can be rapidly overcome. However, it could be argued that it is more appropriate to exclude this parent in the heritabilities used in estimating gain. In this case, the expected gains would be approximately half those above.

Year effects were significant for AA and TPH, although not for fruit weight. Thus, AA and TPH should be measured in more than one year to obtain reliable values. However, the lack of significant year $\times$ genetic effect interactions suggests that ranking of families for AA or TPH should not change substantially between years.

The genotypes used to form the factorial share some common ancestry. The heritability estimates we report may be underestimates of the actual values, since we did not adjust the heritability estimates to account for the parental coancestries. The coancestries among our 42 full-sib families ranged from 0.026 to 0.213 ; hence a uniform inbreeding coefficient could not be used to adjust the variance values used in the estimates. The information reported by Durel et al. (1998) on the heritabilities of agronomic traits in apple indicates that lack of adjustment for parental relatedness resulted in underestimates for heritability. Whether adjusted estimates are more relevant than the unadjusted ones in determining breeding strategy is questionable. Dale et al. (1993) reported that the inbreeding coefficients of 137 red raspberry cultivars released since 1960 from breeding programs throughout the world ranged from 0.0 to 0.625 . Based on the 
coefficients of relationship, the cultivars clustered into 10 groups and the mean inbreeding coefficient for each group ranged from 0.065 to 0.208 . The inbreeding coefficients calculated for the parents in our study are consistent with the range reported by Dale et al. (1993). Thus, the coancestries among the parents in our study are probably similar to the coancestries among parents in red raspberry breeding programs throughout the world. The heritability estimates obtained without adjustment for inbreeding could have more relevance to breeding programs with significant inbreeding than adjusted estimates.

Total phenolic content and AA were highly phenotypically correlated $(r=0.93)$ in this study. As noted above, Liu et al. (2002) and González et al. (2003) also observed high phenotypic correlations. In their survey of Rubus species, Deighton et al. (2000) observed correlations $r=0.96$ between TPH and AA by FRAP assay and $r$ $=0.67$ between TPH and AA by the Trolox equivalent antioxidant capacity (TEAC) assay. Similarly, Moyer et al. (2002), in their survey of Rubus species and cultivars, demonstrated a correlation $r=0.90$ between TPH and AA by FRAP, and $r=0.92$ between TPH and AA by oxygen radical absorbance capacity (ORAC). We obtained a genetic correlation of 0.59 between TPH and AA, suggesting that a substantial additive genetic component underlies these traits, but that sizeable nonadditive components or environmental influences are present as well. While the contributions of individual compounds to the AA in the fruit were not established in this study, there are many phenolic compounds in cane fruit and berry extracts that potentially provide AA, including phenolic acids, flavonols, and anthocyanins. For example, Häkkinen et al., (1999a) reported a high proportion of ellagic acid relative to other phenolic components in red raspberry extracts. Ellagic acid is thought to derive from hydrolysis of the significant amounts of ellagitannins that are present in the fruit and that appear to possess high AA (Mullen et al., 2002). However, González et al. (2003), in their study of four red raspberry cultivars, found no significant correlation between ellagic acid content and AA in fruit extracts, as determined by antiradical efficiency assay. Additionally, non-phenolic compounds, including vitamin C, of which red raspberries contain significant amounts (González et al., 2003; Häkkinen et al., 1999b), also function as antioxidants, and could have contributed to AA in this study. We did not attempt special preservation of vitamin $\mathrm{C}$ content during fruit extraction, so its role in providing AA was not determined. But the contribution of nonphenolic antioxidants to AA in red raspberry might explain why the genetic correlation between TPH and AA is much lower than the phenotypic correlation. Most, but not all, plant phenolics are products of phenylpropanoid metabolism, whereas production of nonphenolic antioxidant compounds, such as vitamin $\mathrm{C}$ or folate, occurs via distinct separate pathways, so nonadditive and environmental factors might influence phenolic and nonphenolic antioxidant production very differently.

Both TPH and AAshowed low but significant inverse phenotypic correlations with fruit weight and very low genetic correlations, indicating there are predominantly environmental or nonadditive genetic causes for the phenotypic correlation. This suggests that breeding to increase TPH or AA will not compromise progress in fruit size, if that is also an objective of the breeding program. Unfortunately, it was beyond the scope of the study to assess other fruit quality traits, such as flavor and color. However, individual anthocyanin levels were measured (unpublished data).

ForTPH and AA, parental sources together accounted for $\approx 13 \%$ to $27 \%$ of the total variation observed among the families, but the relative contribution by females to the total variation differed more than 2-fold between years, while the male effect contribution varied little. The cause for fluctuation between years is not entirely clear. One of the female parents was an offspring of an open-pollinated $R$. parvifolius $\times R$. idaeus hybrid, with fruit that were clearly less pigmented than those of other parents. Many of the offspring of the R. parvifolius derivative parent were also visibly pigment deficient. Since normal anthocyanin pigment production reflects an intact flavonoid synthetic pathway, it is possible, but not requisite, that reduced pigmentation results from abnormal function or regulation of the flavonoid synthetic pathway proximal to the point at which anthocyanin synthase (leucoanthocyanidin dioxygenase) directs flavan-3,4-diol precursors into anthocyanin production. If this were the case, decreased pigmentation in the $R$. parvifolius derivative progeny might be accompanied by altered levels (or altered responses to environmental influences) of the flavonoid compounds arising earlier in the synthetic pathway. Thus, potentially the $R$. parvifolius derivative female parent could have accounted for some of the fluctuation in female source contribution to total variation in TPH and AA between years. When the analyses were repeated following exclusion of $R$. parvifolius derivative progeny, variation among female parents was reduced, but the fluctuation in female parent effect between years remained. Therefore, although this parent clearly contributed considerably to overall variation in TPH and AA among the factorial genotypes, its inclusion does not appear to explain the year-to-year difference in female parent contribution to variation in TPH and AA.

Also observed during the second year of the study was the increased number of plants that required a high number of collections to obtain $100 \mathrm{~g}$ fruit. Eleven factorial genotypes required 5-10 collections to obtain sufficient fruit, and virtually all of these plants were noted for poor vigor, scant new growth, small plant size, low fruit number and slow fruit ripening, suggesting disease or physiological stress. It is possible that the diseased/stressed plants could account for some of the between-year changes in variance for TPH or AA, since phenolic production in the fruit could be altered. For example, a biochemical or structural stress response in the vegetative part of a plant might compel that portion to compete with the fruiting structures for limited photosynthate, decreasing the resources available to the fruit for phenolic synthesis. Conversely, disease or stress that directly affects the fruiting portion of the plant might induce higher phenolic production within the fruit itself. Regardless of cause, exclusion of these 11 genotypes from analysis increased the heritability estimates for TPH and AA by $\approx 10 \%$. This suggests that minimizing stress and disease through good horticultural management can optimize variance analyses and increase heritability and hence the expected gain.

The largest proportion of variation for all three traits was allocated to the residuals, indicating that within-plot genetic and environmental effects, their interactions, and experimental error accounted for most of the variation observed in this population. The within-plot environmental effects were probably small, as the proximity of the two full-sibs minimized differences in exposure. We attempted to reduce experimental error by employing uniform procedures in plant maintenance, fruit collection and extraction, and assay performance, but not all contributions to experimental error were defined or controlled for in this study. We acknowledge that this error could account for considerable within-plot variation, but we propose that the bulk of the large within-plot variances for all three traits was most likely attributable to genetic effects within full-sib families. If this were the case, our data indicate that evaluation of fewer large families, rather than many small 
families, could be used to take advantage of the considerable within-family variation when selecting improved genotypes.

We also noted significant variation among plots within full-sib families, evident in 2003 and in combined-year analysis. Some of this variation may be attributable to genetic (within-family) effects, since each plot contained unique (not cloned) genotypes, and plot means were based on only two individuals. The distribution of within-family plots among four replications, however, suggests that environmental factors and repeated-measure effects in the combined year situation contributed largely to the variation among plots within full-sib families. Thus, it is evident that environment influenced the within-family differences observed in this design. Measures that minimize environmental differences or allow for their adjustment, including evaluating plants in an appropriately chosen design and good plant husbandry, could improve accuracy of evaluation and selection.

\section{Literature Cited}

Age-Related Eye Disease Study Research Group. 2001. A randomized, placebo-controlled, clinical trial of high-dose supplementation with vitamins $\mathrm{C}$ and $\mathrm{E}$, beta- carotene, and zinc for age-related macular degeneration and vision loss: AREDS report no. 8. Arch. Ophthalmology 119:1417-1436.

Benzie, I.F.F. and J.J. Strain. 1996. The ferric reducing ability of plasma (FRAP) as a measure of "antioxidant power": The FRAP assay. Anal. Biochem. 239:70-76.

Commenges, D., V. Scotet, S. Renaud, H. Jacqmin-Gadda, P. Barberfer-Gateau, and J.F. Dartigues. 2000. Intake of flavonoids and risk of dementia. Eur. J. Epidemiol. 16:357-363.

Connor, A.M., J.J. Luby, and C.B.S. Tong. 2002a. Variation and heritability estimates for antioxidant activity, total phenolic content and anthocyanin content in blueberry progenies. J. Amer. Soc. Hort. Sci. 127:82-88.

Connor,A.M., J.J.Luby, and C.B.S. Tong. 2002b. Variability in antioxidant activity in blueberry and the correlations between different antioxidant activity assays. J. Amer. Soc. Hort. Sci. 127:238-244.

Coseteng, M.Y. and C.Y. Lee. 1987. Changes in apple polyphenoloxidase and polyphenol concentration in relation to degree of browning. J. Food Sci. 52:985-989.

Dale, A., P.P. Moore, R.J. McNicol, T.M. Sjulin, and L.A. Burmistrov. 1993. Genetic diversity of red raspberry varieties throughout the world. J. Amer. Soc. Hort. Sci. 118:119-129.

Deighton, N., R. Brennan, C. Finn, and H.V. Davies. 2000. Antioxidant properties of domesticated and wild Rubus species. J. Sci. Food Agr. 80:1307-1313.

Dieters, M.J.J. 1996. Genetic parameters for slash pine (Pinus elliottii) grown in south-east Queensland, Australia: Growth, stem straightness and crown defects. For. Genetics. 3:27-36.

Durel C.E., F. Laurens, A. Fouillet, and Y. Lespinasse. 1998. Utilization of pedigree information to estimate genetic parameters from large unbalanced data sets in apple. Theor. Appl. Genet. 96:1077-1085.

Fejer, S.O. 1977. Inheritance of yield, yield components, and fall-fruiting habit in red-raspberry diallel crosses. Can. J. Genet. Cytol. 19:1-13.

Fejer, S.O. and L.P.S. Spangelo. 1974. Three generations of inbreeding and $\mathrm{S}_{2}$ factorial test crosses in red raspberry cultivars. Can. J. Genet. Cytol. 16:419-432.

Geleijnse, J.M., L.J. Launer, D.A. Van der Kuip, A. Hofman, and J.C. Witteman. 2002. Inverse association of tea and flavonoid intakes with incident myocardial infarction: The Rotterdam study. Amer. J. Clinical Nutr. 75:880-886.

González, E.M., B. de Ancos, and M.P. Cano. 2003. Relation between bioactive compounds and free radical-scavenging capacity in berry fruits during frozen storage. J. Sci. Food Agr. 83:722-726.

Häkkinen S.H., M. Heinonen, S. Kärenlampi, H. Mykkänen, J. Ruus- kanen, and R. Törrönen. 1999a. Screening of selected flavonoids and phenolic acids in 19 berries. Food Res. Intl. 32:345-353.

Häkkinen, S.H., S.O. Kärenlampi, I.M. Heinonen, H.M. Mykkänen, and A.R. Törrönen. 1999b. Content of the flavonols quercetin, myricetin, and kaempferol in 25 edible berries. J. Agr. Food Chem. 47:2274-2279.

Hallauer, A.R. and J.B. Miranda. 1981. Hereditary variances: Mating designs, p. 45-113. In: Quantitative genetics in maize breeding. Iowa State Univ. Press, Ames,.

Hertog, M.G.L., E.J.M. Feskens, and D. Kromhout. 1997. Antioxidant flavonols and coronary heart disease risk. Lancet 349:699.

Howard, L.R., J.R. Clark, and C. Brownmiller. 2003. Antioxidant capacity and phenolic content in blueberries as affected by genotype and growing season. J. Sci. Food Agr. 83:1238-1247.

Hirvonen, T., P. Pietinen, M. Virtanen, M.L. Ovaskainen, S. Häkkinen, D. Albanes, and J.Virtamo. 2001. Intake of flavonols and flavones and risk of coronary heart disease in male smokers. Epidemiology 12:62-67.

John, J.A. and E.R. Williams. 1995. Cyclic and computer generated designs. Chapman and Hall, London.

Joseph, J.A., B. Shukitt-Hale, N.A. Denisova, D. Bielinski, A. Martin, J.J. McEwen, and P.C. Bickford. 1999. Reversals of age-related declines in neuronal signal transduction, cognitive, and motor behavioral deficits with blueberry, spinach, or strawberry dietary supplementation. J. Neuroscience 19:8114-8121.

Kähkönen, M.P., A.I. Hopia, and M. Heinonen. 2001. Berry phenolics and their antioxidant activity. J. Agr. Food Chem. 49:4076-4082.

Kähkönen, M.P., A.I. Hopia, H.J. Vuorela, J-P. Rauha, K. Pihlaja, T.S. Kujala, and M. Heinonen. 1999. Antioxidant activity of plant extracts containing phenolic compounds. J. Agr. Food Chem. 47:3954-3962.

Knekt, P., J. Kumpulainen, R. Järvinen, H. Rissanen, M. Heliövaara, A. Reuanen, T. Hakulinen, and A. Aromaa. 2002. Flavonoid intake and risk of chronic diseases. Amer. J. Clinical Nutr. 76:560-68.

Liu, M., X.Q. Li, C. Weber, C.Y. Lee, J. Brown, and R.H. Liu. 2002. Antioxidant and antiproliferative activities of raspberries. J. Agr. Food Chem. 50:2926-2930.

Middleton, Jr., E., C. Kandaswami, and T.C. Theoharides. 2000. The effects of plant flavonoids on mammalian cells: Implications for inflammation, heart disease, and cancer. Pharmacological Rev. 52:673-751.

Moyer, R.A., K.E. Hummer, C.E. Finn, B. Frei, and R.E. Wrolstad. 2002. Anthocyanins, phenolics, and antioxidant capacity in diverse small fruits: Vaccinium, Rubus, and Ribes. J. Agr. Food Chem. 50:519-525.

Mullen, W., J. McGinn, M.E. Lean, M.R. MacLean, P. Gardner, G.G. Duthie, T. Yokota, and A. Crozier. 2002. Ellagitannins, flavonoids, and other phenolics in red raspberries and their contribution to antioxidant capacity and vasorelaxation properties. J. Agr. Food Chem. 50:5191-5196.

Nestby, R. 1994. Heritability estimates in raspberry breeding, p. 211-213. In: H. Schmidt and M. Kellerhals (eds.). Progress in temperate fruit breeding. Kluwer Academic, Boston.

Poehlman, J.M. and D.A. Sleper. 1995. Quantitative inheritance in plant breeding, p. 60-82. In: Breeding field crops. Iowa State Univ. Press. Ames.

Proteggente, A.R., A.S. Pannala, G. Paganga, L. van Buren, E. Wagner, S. Wiseman, F. van de Put, C. Dacombe, and C.A. Rice-Evans. 2002. The antioxidant activity of regularly consumed fruit and vegetables reflects their phenolic and vitamin $\mathrm{C}$ composition. Free Radical Res. 36:217-233.

Satterthwaite, F.E. 1946. An approximate distribution of estimates of variance components. Biometrics. 2:110-114.

Steel, R.G.D., J.H. Torrie, and D.A. Dickey. 1997. Principles and procedures of statistics: A biometrical approach. MacGraw-Hill, New York.

Wada L. and B. Ou. 2002. Antioxidant activity and phenolic content of Oregon caneberries. J. Agr. Food Chem. 50:3495-3500.

Wang, H., G. Cao, and R.L. Prior. 1996. Total antioxidant capacity of fruits. J. Agr. Food Chem. 44:701-705. 